\title{
Window to the Future or Door to Chaos?
}

\author{
Marcelo Antônio Cartaxo Queiroga Lopes, ${ }^{1}$ Gláucia Maria Moraes de Oliveira, ${ }^{2}$ Alberto Amaral Júnior, ${ }^{3}$ Eitel \\ Santiago de Brito Pereira ${ }^{4}$ \\ Hospital Metropolitano Dom José Maria Pires, ${ }^{1}$ João Pessoa, PB - Brazil \\ Universidade Federal do Rio de Janeiro, ${ }^{2}$ Rio de Janeiro, RJ - Brazil \\ Universidade de São Paulo, ${ }^{3}$ São Paulo, SP - Brazil \\ Universidade Federal da Paraíba, ${ }^{4}$ João Pessoa, PB - Brazil
}

The remarkable advance in technology has caused a new social revolution impacting all areas of knowledge, modifying traditions and practices that were consecrated centuries ago. Advances in informatics and telecommunications with practical application in various sciences are eloquent examples of such transformation. ${ }^{1}$

In medicine, this progress has brought up extraordinary advances in diagnosis and therapy, since the combination of new medical technologies and efficient communication media has bequeathed us telemedicine, which has been practiced for more than two decades with great success, opening the doors for solutions such as a telematic transmission of a simple electrocardiogram to remotely performing robotic surgeries. ${ }^{2}$

In this scenario, the need for regulation of telemedicine in Brazil arose. The Brazilian federal legislation handed over such attribution to the Federal Medical Council (Conselho Federal de Medicina, CFM), which performed it by issuing CFM Resolution 2.227/2018, ${ }^{3}$ already published in the Union Official Gazette (Diário Oficial da União).

In the aforementioned resolution, CFM defined in Article 1 telemedicine as "the practice of medicine mediated by technologies for assistance, education, research, prevention of diseases and injuries, and health promotion." The Council is fully aware of possible benefits that can result of an ethical application of this practice, which can broaden access to public health and maximize the effects of already established public policies. That was why the Council issued the regulations, but it must be aware of the disruptive power of this technology, which confronts, in theory, millennial postulates of professional practice. Medicine, as conceived, does not dispense with physician-patient interaction. Therefore, telemedicine cannot dispense the doctor or replace him with another professional in the practice of those acts that, under the terms of Law $12.842 / 2013,{ }^{4}$ are exclusively to physicians.

The CFM uses the term teleconsultation as a shelter of telemedicine. The word sounds like a situation where a name comes to have a life of its own as something justifiable,

\section{Keywords}

Medicine/trends; National Science, Technology and Innovation Policy; Technological Development/ethic; Telemedicine/ legislation \& jurisprudence; Delivery Health Care/legislation \& jurisprudence; Precision Medicine/trends.

Mailing Address: Marcelo Antônio Cartaxo Queiroga Lopes • Cardiocenter - Av. Ministro José Américo de Almeida, 1450, Torre, Hospital Alberto Urquiza Wanderley. Postal Code 58.040-300, João Pessoa, PB - Brazil E-mail:mqueiroga@cardiol.br, marcelocartaxoqueiroga@gmail.com Manuscript received February 19, 2019, revised manuscript February 19, 2019, accepted February 19, 2019 routine, as if it had always existed and dispensed a critical analysis of its origins. However, novelty should not be understood in this way. There are challenges of a technical, ethical, legal, regulatory, and cultural nature regarding teleconsultation, which is exclusive of the physician and requires access to medical records, or in other words, to the set of standardized and ordered documents that the patient might have from a previous care. It is important to emphasize that access to medical record is among the exclusive acts of the physician and the patient has the right to demand that the data recorded are kept secret. ${ }^{5}$

Classically, a consultation includes the triad anamnesis, physical examination, and complementary tests in an integrated and "carousel" dynamic. Thus, physical examination findings, for example, may motivate a return to anamnesis; the image reports, in turn, can determine the making of another physical examination, etc. Who decides this dynamic is traditionally the doctor, who assumes responsibility for his decisions. Now, the teleconsultation can make the physical examination unfeasible, since the doctor will be away from the patient. In this case, who will take responsibility? Will the doctor sitting in front of a computer have a duty to raise an objection of conscience not to proceed? Nowadays, even in well-known cases, prudence - a cornerstone of ethics - suggests that a face-to-face interaction is needed in most cases. ${ }^{5}$

Would the patient be well informed that the teleconsultation and any other methods of telemedicine may represent an incomplete methodology, especially if they involve the waiver or substitution of an actual physician by another type of professional? Would the patient take responsibility for any failures resulting from this new form of assistance and still give consent? Would the lack of a detailed anamnesis, such as those commonly done in traditional consultations, or the shortage of documentary records, not weaken the acts of telemedicine? Incidentally, by documentary evidence, the role of the medical record as a memory, or thread leading to an efficient diagnosis, has the potential to be impaired in the inadequate practice of telemedicine procedures, which can be damaging.

CFM regulation should therefore represent a step forward, not a setback. Broadening access in public health is a common desire of all physicians. In this nuance, telemedicine brings indisputable progress, which justifies its regulation. However, CFM should be vigilant so that everything is done properly, with technical quality discretion, anticipating the regulatory impact of the standard. Regulation should preserve, for example, the millenary postulates of the practice of medicine and promote equality. The major challenge of CFM Resolution $2.227 / 2018^{3}$ is to be effective and applicable in the advance of social justice and deliberative ethics.

DOI: $10.5935 / a b c .20190056$ 
The medical consultation materializes the doctor-patient interaction. Interaction that gains strength because it is based on the confidence of the patient and the conscience of the doctor. These are the bases of respectability of medicine over time.

The CFM, through CFM Resolution 1958/2010, ${ }^{6}$ announced that the consultation includes acts such as "anamnesis, physical examination, and elaboration of hypotheses or diagnostic conclusions, request for complementary tests, when necessary, and therapeutic prescription as a complete medical act that can be finished or not in a single moment."

The Code of Medical Ethics, ${ }^{7}$ in turn, prohibits the prescription of treatment without prior examination of the patient. Here is the precept:

"Art. 37. To prescribe treatment or other procedures without direct examination of the patient, except in cases of urgency or emergency and a proven impossibility to perform it, and in this case, to do so immediately after cessation of the disability."

The rules can be harmonized because the sole paragraph of this deontological norm speaks of "remote medical care, in the form of telemedicine or other method," determining to do so with respect to the regulations of the CFM.

In establishing the conditions for the practice of telemedicine by doctors in Brazil, the CFM presented a new ethical framework for the practice of medicine in the country. The changes, inserted in the Resolution, update the Code of Medical Ethics, making the old regulation seem like a fossil, in view of the potential for interference of the new digital ethics in medical practice.

The Code of Medical Ethics ${ }^{7}$ is a rule that has the same hierarchy as CFM Resolution 2.227/2018. ${ }^{3}$ Thus, although considered as the major ethical guide, it is not possible to say that the telemedicine Resolution confronts the Code of Medical Ethics in some of its devices, especially in relation to the need for a direct examination of the patient before the prescription, as established in Article 37 of the Code of Ethics.

The major problem of the rule in question would be in the teleconsultation, regulated in Article 4, because it dispensed the face-to-face examination of the patient prior to the prescription. Although the need for a previous physical examination has not been completely abolished, since Paragraph 1 "implies as a mandatory premise" that the first visit is compulsory, and a new on-site visit is recommended every 120 days. However, the new rule allows for virtual consultation when practicing healthcare coverage to remote sites, where, in theory, there would be a shortage of human resources. It should be noted that, to a certain extent, the same argument was used in the Mais Médicos Program, when the revalidation of the diploma of doctors graduated abroad was dispensed in order for them to work in the Unified Health System (Sistema Único de Saúde, SUS). Teleconsultation is regulated as follows, in verbis:

"Art. 4 Teleconsultation is the remote medical consultation, mediated by technologies, with doctor and patient located in different geographic spaces.

$\S 1$ Teleconsultation implies as a mandatory premise the prior establishment of a face-to-face relationship between doctor and patient.
$\S 2$ In long-term visits or chronic diseases, it is recommended to consult face-to-face at intervals not exceeding 120 days.

$\S 3$ The establishment of a physician-patient relationship in a virtual way is permitted for healthcare coverage in geographically remote areas, provided there are the recommended physical and technical conditions and health professional.

$\S 4$ Telemedicine must be duly consented by the patient or his legal representative and performed by free decision and under the professional responsibility of the physician.

$\S 5$ In case of participation of other health professionals, they must receive adequate training, under the responsibility of the physician, individual, or technical director of the intermediary company."

Resolution $2.227 / 2018^{3}$ has found strong resistance among physicians, mainly due to its transformative potential. Healthcare providers, large hospitals, and telemedicine solutions companies are euphoric. At the other end, doctors claim that medicine suffered a severe blow for those who had an ethical duty in their practice, turning doctors into true telemarketers.

The detailed and impartial analysis of the Resolution in question points, as already mentioned, to an apparent confrontation with the rules of the Code of Medical Ethics. But by far the greatest problem would arise from the existence of possible offenses to the legal system, as verified in Paragraph 5 of Article 4. There, we can see a delegation of medical powers to other health professionals, such as nurses. At this point, the defect of the norm is not only in the possible offense to Article 2 of the Code of Medical Ethics. It goes further, challenging fences imposed by the law.

The Federal Constitution of $1988^{8}$ ensures in Item XIII of Article 5 the freedom of professional practice, provided that it is practiced "according to the professional qualifications established by law." However, as the law defines what acts are exclusive to doctors, it arises the illegality of the norm contained in the CFM Resolution, which confers additional competence to other health professionals - nurses for example - to practice acts that are exclusive to the physician.

It is known that the Law No. 7.498, from June 25, 1986, ${ }^{9}$ which provides for the practice of nursing in Brazil, defines, in Article 1, the practice of that profession throughout the national territory, within the limits of the law. It is not ignored that Article 11 of the aforementioned law attributes to the nurse, as a member of the health team, the competence to prescribe drugs established in public health programs and routinely approved by the health institution. What is said is that the legislation does not attribute to nurses the assignment to participate in teleconsultation, as did CFM in Paragraph 5 of Article 4 of the Resolution discussed.

In other words, Paragraph 5 of Article 4 of the Resolution ${ }^{3}$ considered provides for the participation of other health professionals, including nurses, in acts exclusive to doctors, in the case of medical consultation, even in its remote version. Neither would the distinguished CFM have the legal competence to assign to the doctor or technical director of "intermediary company" the prerogative to train other health professionals, whose professions are regulated and governed by their own legal system. 
Paragraph 3 of the same Article 4 of the aforementioned resolution allows the "establishment of a virtual doctor-patient relationship" only for health care coverage in geographically remote areas, provided that there are the recommended physical and technical conditions, as well as healthcare professionals.

The argument that teleconsulting fulfills the difficulty of healthcare assistance due to geographic distance requires clarification of the meaning of distance, so that it does not fit something that can be face-to-face, but that presents difficulties of access, for being far, for having complicated transit, for demanding assistance at times incompatible with the availability of the physician, etc. In short, comfort should not serve as justification for the acceptance of an incomplete care from the point of view of identification of signs and symptoms.

It is clear that the new rule has yet to define the meaning of geographically remote areas, leaving room for broader interpretations of the possibilities of the teleconsultation, which cannot lose its merely complementary character, to meet the needs of the assistance of a country of continental dimensions, transforming itself into powerful tool for curtailing patients' rights. That is, teleconsulting, assuming its legality, is only justified to expand access to unserved beneficiaries of the SUS.

On the other hand, in the scope of Supplementary Health, Law 9.656, dated June 3, 1998, ${ }^{10}$ which provides for private healthcare plans and insurance, establishes a specific regulatory framework, provided for in the contractual sphere, distinct from the commitment to universal access, provided for in Article 196 of the Federal Constitution. Therefore, the coverage limits of the beneficiaries of the health plan operators are clearly defined by law.

The National Agency of Supplementary Health (Agência Nacional de Saúde Suplementar, ANS), which is responsible for regulating the sector and elaborating the Role of Procedures and Events in Health, or Role of Procedures, has already decided that medical consultation is one of the compulsory coverage procedures. Also, teleconsultation could not be used to replace the essential face-to-face consultation, which the beneficiary is totally burdened with, to be used to restrict access to the clear legal right.

Still resorting to Law $7.498 / 1986,{ }^{9}$ it is clear that the nurse only has legal competence to prescribe "medications established in public health programs and routinely approved by the health institution." Thus, even if it is alleged that the responsibility for the eventual prescription in teleconsultation is of the doctor who is at a distance, the other health professional who also attends the medical act, also participates, in full exercise of his profession, therefore, must behave within the legal limits of the law.

It seems that, in the scope of supplementary health, there is no legal support, for example, for nurses, even under supervision, to prescribe medications or request tests, and the realization of a teleconsultation, with the participation of other health professionals, would be a practice without support in the legislation. ${ }^{10}$

The publication of Resolution 2.227/2018 ${ }^{3}$ caused uneasiness, since it is necessary to start from a premise: teleconsultation can only be done when the doctor already knows the patient. Necessary, therefore, a prior consultation in which there was a previous face-to-face relation between doctor and patient. However, the presence of this requirement will be difficult to control and oversight, because knowing the patient does not mean knowing the case of the moment. Thus, first-time consultations of the clinical situation are likely to be "confused" with a follow-up consultation, where one could accept the non-presence for information about progression, therapeutic adjustments, and evaluation of the requested tests.

Law 12.871, of October 22, 2013, ${ }^{11}$ which established the Mais Médicos Program, allowed the revalidation of the medical diploma not to be compulsory in the strict context of this program. That is, Resolution $2.227 / 2018^{3}$ should make it clear that only in the context of public programs, once the absence of doctors is verified, it would be possible to teleconsult without another doctor with the patient.

It is believed that Hippocrates removed medicine from the gods exactly to allow interaction between humans. We now run the risk of the "deification" of technology to extrapolate its undeniable utility of data transmission within ethical standards. Thus, from the transdisciplinary point of view, about its three foundations - rigor, openness, and tolerance - there is a high risk of compromising technoscientific rigor. $^{5}$

The CFM, when editing the Resolution, embraces the unknown, the unexpected, disregarding the tolerance of opposing opinions, which may arise in the complex process of decision making, in the face of the patient's right to the active voice, when he dialogues directly with the doctor.

Concerning the two important pillars of medical ethics, it is a matter of concern to deal with prudence - caution during the decision-making process - and with zeal - quality of application and observance of the evolution of consensual conduct. Concerning three of the principles of bioethics, it concerns the management of beneficence as well as non-maleficence - that today, because any method is liable to cause harm, has become synonymous with security, in addition to bringing new aspects about autonomy. ${ }^{5}$ Finally, does the teleconsultation pass through the sieve of the ten steps ${ }^{12}$ essential for a qualified clinical diagnosis in the context of anamnesis-physical examination integration?

It is worth remembering the decalogue that must be observed in order to prepare a good diagnosis: (1) an overall view of the patient made possible by physical proximity; (2) patient's free issue of his complaints and impressions; (3) physician-patient dialogue stimulated to clarify obscure points and hypotheses raised by the physician based on what the patient said; (4) construction of diagnostic hypotheses supported by anamnesis; (5) performing the physical examination and identifying, or not, signs aligned with the hypotheses, or expanding to new hypotheses; (6) return to anamnesis when indicated by physical examination findings that compose new clinical reasoning; (7) evaluation of the need and selection of complementary examination based on anamnesis-physical examination integration; (8) integration of the reports of complementary tests with the clinical reasoning sustaining the request of the tests; (9) formulation of the probable diagnosis; and (10) use as a basis for therapeutic conduct, always remembering to clarify the patient well so 
that he can give or not give consent, which should not be obtained at the outset as a carte blanche. ${ }^{12}$

Essential questions need to be well defined: (1) level of biological safety for the patient; (2) level of ethical and legal safety for the physician; (3) impact on physician training; (4) impact on society's habits. ${ }^{5}$

Another point worth mentioning is telesurgery, provided for in Article 8 and defined as "performing a remote surgical procedure, mediated by safe interactive technologies, with medical executor and robotic equipment in distinct physical spaces." "3 Telesurgery is only possible due to robotic surgery, whose clinical application in Brazil is still restricted, being that most parts of the techniques lack assessment by the CFM.

In order to be effective, it is imperative that the medical team be composed, at least, of the robotic equipment (remote surgeon) and physician responsible for the instrumental manipulation (local surgeon), both of whom must be specialists with Specialist Qualification Registry (Registro de Qualificação de Especialista, RQE) in the area corresponding to the main surgical act, registered with the Regional Council of Medicine (CRM) of its jurisdiction, excluding, at least in theory, the performance of telesurgery by physicians not enrolled in the CRM in other countries. ${ }^{3}$

The legal competence to define the experimental nature or not of medical procedures is of the CFM, with a focus on Law 12.842/2013, ${ }^{4}$ embodied in Article 7 , authorizing or prohibiting its practice by doctors in Brazil. In this way, it would be appropriate to insert a device in the resolution restricting the practice of robotic telesurgery to techniques already approved by CFM and in current use in the country, since it would be unreasonable to offer something with restricted availability frustrating the fair expectations of the medical profession and Brazilian society.

It is worth mentioning that none of the techniques of robotic surgery is part of Brazil's public policy roll, nor are they included in the ANS Health Procedures and Events Role. In other words, the expansion of the robotic surgery care network, without even being predicted coverage in the country, can inaugurate the "tele-judicialization" of health, a new way of reversing priorities in the country's health system.

Finally, it is opportune to discuss Article 9, which regulates the diagnosis: "Telediagnosis must be carried out according to scientific guidelines proposed by the Association of Specialty linked to the method, recognized by the Joint Commission of Specialties, constituted according to Decree No. 8.516, of September 10, 2015. ${ }^{\prime 13}$ In this sense, it is important to note that Law 12.401, dated April 28, 2011, ${ }^{14}$ defines that the competence to elaborate clinical protocols and therapeutic guidelines ${ }^{\mathrm{a}}$ within the scope of the SUS is of the National Commission for the Incorporation of Technologies in the SUS (Comissão Nacional de Incorporação de Tecnologias, Conitec).

Conitec, based on the discussed legislation, has legal attribution for the elaboration of clinical protocols and therapeutic guidelines. The CFM could not, based on a normative resolution, exclude those who have legal competence to elaborate guidelines within the Brazilian health system, delegating exclusively this attribution to private entity, even if conditioned to its approval. The improvement of the standard in this regard is becoming more pressing.
Moreover, it would not be too much to say that Resolution $2.227 / 2018^{3}$ does not have the power to legitimize, broadly speaking, the incorporation of telemedicine in Brazil, but only regulates the participation of physicians in its practice. The entry of any technology according to current legislation, this includes telemedicine, will necessarily consider:

I. the scientific evidence on the efficacy, accuracy, effectiveness, and safety of the medication, product, or procedure that is the subject of the proceedings, which is complied with by the entity responsible for registration or authorization for use;

II. the comparative economic evaluation of the benefits and costs in relation to technologies already incorporated, including with regard to home, outpatient or hospital care, when appropriate."

Resolution 2.227/2018, ${ }^{3}$ although necessary, as it is drafted, unless it is better judged, confronts the domestic legislation that regulates the other health professions, as discussed, and should be modified, at least as far as the wording of Articles 4,8 , and 9 are concerned. In our understanding, the wording below would be more appropriate for the opportunity and species. The adequation below would be reasonable as a way of making compatible the already published norm and the set of theses defended in this article:

Art. 4 Teleconsultation is the remote medical consultation, mediated by technologies, with doctor and patient located in different geographic spaces.

$\S 1$ In teleconsultation, the prior establishment of a face-to-face relationship between doctor and patient is a mandatory premise.

$\S 2$ In long-term care or chronic diseases, it is recommended to consult face-to-face at intervals not exceeding 120 days.

$\S 3$ The establishment of a doctor-patient relationship in a virtual way is permitted exclusively for health care coverage in geographically remote areas, provided that there are the recommended physical and technical conditions and legally qualified health profissional.

$\S 4$ For the purposes defined in this article, it is the responsibility of the Regional Councils of Medicine within their jurisdictions to define, in their own act, which are the geographically remote areas.

$\S 5$ The teleconsultation must be duly consented by the patient or his legal representative and performed by free decision and under the professional responsibility of the physician.

$\S 6$ In case of participation and training of other health professionals, the requirements of the legislation that regulates their respective professions must be met.

$\S 7$ Teleconsultation is prohibited in the scope of supplementary health.

Article 8

(...)

$\S 10$ Surgical procedures not evaluated or considered experimental by the Federal Council of Medicine should be carried out in research protocols according to the rules of the CEP/CONEP System.

a II - Clinical protocol and therapeutic guideline: document that establishes criteria for the diagnosis of the disease or health problem; the recommended treatment, with the medications and other appropriate products, when applicable; the recommended dosages; the mechanisms of clinical control; and the monitoring and verification of the therapeutic results, to be followed by administrators at the SUS. 
Art. 9 Telediagnosis must be carried out according to scientific guidelines approved by the National Commission for the Incorporation of Technologies in the SUS (Conitec) or proposed by the Specialty Association linked to the method, recognized by the Joint Commission of Specialties, constituted according to Decree $N^{\circ}$. 8.516, of 10 September2015. ${ }^{13}$

Prior to the publication of this article, CFM, for the reasons discussed here, revoked the Resolution $2.227 / 2018^{3}$ to allow its goal to materialize in practice, and the appropriate regulation of extraordinary telemedicine be no longer a promise, becoming an instrument of equity and social justice, ${ }^{15,16}$ under risk of telemedicine becoming, instead of a window into the future, a door to chaos.

\section{Author contributions}

Conception and design of the research, Acquisition of data, Analysis and interpretation of the data, Writing of the manuscript and Critical revision of the manuscript for intellectual content: MACQ Lopes, Oliveira GMM, Amaral Júnior A, Pereira ESB

\section{Potential Conflict of Interest}

No potential conflict of interest relevant to this article was reported.

\section{Sources of Funding}

There were no external funding sources for this study.

\section{Study Association}

This study is not associated with any thesis or dissertation work.

\section{Ethics approval and consent to participate}

This article does not contain any studies with human participants or animals performed by any of the authors.

\section{References}

1. Topol EJ. High-performance medicine: the convergence of human and artificial intelligence. Nat Med. 2019;25(1):44-56.

2. de la Torre-Díez I, López-Coronado M, Vaca C, Aguado JS, de Castro C. Cost-utility and cost-effectiveness studies of telemedicine, electronic, and mobile healthsystems in the literature: a systematic review. Telemed J E Health. $2015 ; 21(2): 81-5$

3. Conselho Federal de Medicina (CFM-Brasil). Resolução CFM 2.227/2018: define e disciplina a telemedicina como forma de prestação de serviços médicos mediados por tecnologia. [Acesso em 15 fevereiro 2019]. Disponível em:https://portal.cfm.org.br/images/PDF/resolucao222718.pdf

4. Brasil. Presidência da República. Lei № 12.842, de 10 de julho de 2013. [Acesso em 15 fevereiro 2019]. Disponível em: http://www.planalto.gov.br/ ccivil_03/Ato20112014/2013/Lei/L12842.htm

5. Chaet D, Clearfield R, Sabin JE, Skimming K; Council on Ethical and Judicial Affairs American Medical Association. Ethical practice in Telehealth and Telemedicine. J Gen Intern Med. 2017;32(10):1136-40.

6. Conselho Federal de Medicina (CFM-Brasil). Resolução CFM Resolução CFM no 1.958/2010. [Acesso em 15 fevereiro 2019]. Disponível em:http:// www.portalmedico.org.br/resolucoes/cfm/2010/1958_2010.htm.

7. Conselho Federal de Medicina (CFM- Brasil. Código de Ética Médica. [Acesso em 15 fevereiro 2019]. Disponível em: https://sistemas.cfm.org. br/normas/visualizar/resolucoes/BR/2018/2217.

8. Brasil. Constituição. Constituição da República Federativa do Brasil de 1988. [Acesso em 15 fevereiro 2019]. Disponível em: http://www.stf.jus. br/arquivo/cms/legislacaoconstituicao/anexo/cf.pdf

9. Brasil. Lei № 7.498 de 25 de junho de 1986: Dispõe sobre a regulamentação do exercício da Enfermagem e dá outras providências. [Acesso em 15 fevereiro 2019]. Disponível em:http://www.planalto.gov.br/ccivil_03/LEIS/L7498.htm.
10. Brasil. Lei № 9.656 de 03 de junho de 1998: Dispõe sobre os planos e seguros privados de assistência à saúde. [Acesso em 15 fevereiro 2019]. Disponível em: http://www.planalto.gov.br/ccivil_03/LE. 56.htm.

11. Brasil. Lei № 12.871 de 22 de outubro de 2013. Altera as leis № 8.745 de 08 de dezembro de 1993, e № 6.932 de 07 de julho de 1981, e dá outras providências. [Acesso em 15 fevereiro 2019]. Disponível em:http://www. planalto.gov.br/ccivil_03/_Ato2011-2014/2013/Lei/L12871.htm.

12. Grinberg M. Bioética e troca de mensagens por aplicativo WhatsApp sempre alerta na palma da mão. Arq Bras Cardiol: imagem cardiovasc. 2018;31(3):126-9.

13. Brasil. Lei № 8516 de 10 de setembro de 2015. Regulamenta a formação do cadastro nacional de especialistas de que tratam o $\S 4$ e e $\S 50$ do art. 10 da lei 6.932 de 07 de julho de 1981, e o art. 35 da Lei № 12.871, de 22 de outubro de 2013. [Acesso em 15 fevereiro 2019]. Disponível em: http://www.planalto.gov.br/ccivil_03/_Ato2015-2018/2015/Decreto/ D8516.htm.

14. Brasil. Lei № 12.401 de 28 de abril de 2011. Altera a Lei № 8.080 , de 19 de setembro de 1990, para dispor sobre a assistência terapêutica e a incorporação de tecnologia em saúde no âmbito do Sistema Único de Saúde (SUS). [Acesso em 15 fevereiro 2019]. Disponível em: http://www.planalto. gov.br/ccivil_03/_Ato2011-2014/2011/Lei/L12401.htm.

15. Andrade MV, Maia AC, Cardoso CS, Alkmim MB, Ribeiro AL. Cost benefit of the telecardiology service in the state of Minas Gerais: Minas Telecardio Project. Arq Bras Cardiol. 2011;97(4):307-16.

16. Oliveira Jr. MT, Canesin MF, Marcolino MS, Ribeiro ALP, Carvalho ACC, Reddy S et al. Sociedade Brasileira de Cardiologia. Diretriz de Telecardiologia no Cuidado de Pacientes com Síndrome Coronariana Aguda e Outras Doenças Cardíacas. Arq Bras Cardiol 2015; 104(5Supl.1): 1-26 